construction. The nature and size of the engines and machinery required for each. The ordnance and armament necessary for each. The appropriate equipment and rigging of each. The internal arrangements of each; and upon such other details as may seem to be the whole of each vessel when complete and ready for service.

This board reported to the Navy Department in November following, but only unarmored vessels were considered and reported upon at the time, as "the order explicitly stated that the necessities of the present time were to be provided for." These recommendations were laid before Congress, but there was no appropriation made for the increase of the navy at that session of Congress, as the bill for its relief contained some radical provisions that prevented its passage. The second Naval Advisory Board, consisting a five The second Naval Advisory Board, consisting through an act of Congress, was organized in Novem through an act of Congress, was organized in Novem- building of the three cruisers, the "Chicago," the "Atlanta," the "Boston," and the dispatch boat "Dolphin." The "Chicago" was a steel twin-screw, coalprotected cruiser, having a steel protective deck 11/2 inches thick on the flat, 1 foot above load waterline, and 12 feet from the side it was bent downward to ward the hull. The "coal armor" was about 9 feet thickness, and was located just above the curved por tion of the protec thon the protective deck. The turrets were unarmored. The only protection for the men operating th guns was afforded by steel shields placed on the guns The "Boston" and the "Atlanta" were each single screw vessels of steel, having a protective steel deck $1 \frac{1}{2}$ inches thick covering the machinery and boile spaces, and having a coal armor nearly the same as in the "Chicago." The main-deck structure, covering th main battery of the vessel, was plated with $3 /$-inch steel, and the open guns fore and aft on main deck were protected by an armored mantlet as protection from machine guns. The "Dolphin" is a single-screw vessel of steel also. As the governing condition in the design of this vessel was for high speed to be maintained for several days, there was no attempt whatever made at protection of the vessel. She may be said to be on the design of a high-speed merchant vessel.

At the commencement of the building of these ves. sels, it was found that the steel manufacturers were unable to fill the orders for the structural material until they had made extensive additions to their plants in many instances. They were not as well prepared for the work as they had supposed. The large sizes of shapes, and the heavy plating required, with the stringent requirements of the contracts in the quality of the material, etc., created some delay in the delivery. They were unable at first to produce a uniform grade of steel of contract demands, but experience soon overcame the difficulty. The limited experience of the inspectors, with their very rigid inspections of the material for the Navy Department, was an additional terial for the Navy Department, was an additional
cause of delay. It was new work for the steel manufacturers as well as the inspectors. (To be continued.)

\title{
DUST PREVENTION IN THE GRINDING TRADES.
}

\section{SOME IMPROVED METHODS.}

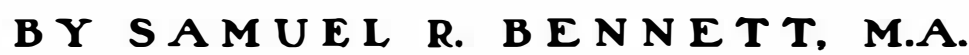

In the course of an investigation carried out by the order of Dr. Whitelegge, Chief Inspector of Factories, Home Office, with a view to devising methods of re moving and allaying dust arising in the Sheffield cut lery and kindred grinding trades, some improvements have been made on the existing methods. Two of these improved methods are noteworthy, because thei iffects are far reaching. They are (1) a wet method of "racing" grindstones when first hung, and (2) an improved form of hood for catching dust, etc., given off in the processes of dry grinding.

Many varieties of grindstones are used in Sheffield. Some are huge masses, seven feet in diameter when

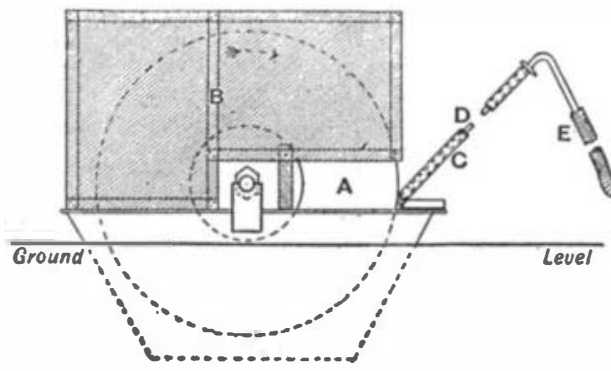

Fig. 1.-WET RACING APPARATUS

A. Grindstone. B. Splash box. C. Racing pipe. D. Inner tnbe.
E. Flesible hose (to water. tap).

new and twelve inches or more in thickness, and are used in saw-grinding, etc. Others are used when little
more than seven inches in diameter and one inch more than seven inches in diameter and one inch
across. Some are almost of a flinty hardness, while others could almost be crumbled in the hands.

The troughs in which the stones revolve are sunk into the floor so that approximately three-fifths of the stone is above the floor level, allowing for the spindle bearings over the trough. All stones are hung on spindles and centered thereon. This centering, when the stones are small, is done by means of wedges the stones are small, is done by means of wedges
between the spindles and the central holes in the stones. For almost all wet stones above twelve inches in diameter circular side-plates are used. These are screwed up against the sides, after the rough quar ried stones have been approximately balanced on the axles. The remaining irregularities, chisel-marks, eccentricities, etc., from the true cylinder, are removed by the process of "racing." To perform this operation the grinder places a short piece of wooden plank close the grinder places a short piece of wooden plank close
to the face of the slowly revolving stone. Using an to the face of the slowly revolving stone. Using an
iron or steel rod pointed at the end as a lever he firmly holds the point against the stone; thus th projecting parts of stone are broken away. By rolling the lever on the plank the whole face of the stone is trued up. The sides are then similarly dealt with.

Up to the present time racing has been done with the stone and apparatus in a dry state. Any person who has been in a grinding hull or room while dry racing was being done will have experienced the suffocating clouds of swirling dust which penetrate to very corner. The dust is almost wholly siliceous, and has an irritant effect on the nostrils and throat It covers thickly everything and everybody in the hull. Much remains suspended in the air for ove an hour after the racing is finished. The baneful effect on the lungs of the grinders is easily under stood.

Mr. C. F. R Johnston, H.M. Inspector of Factories, and the writer tried many kinds of apparatus-some ngenious, some expensive, most of them cumbersomefor racing a grindstone without making much dust. We found none that came within our requirements.
At length we devised the following method which has the merits of being effective and cheap, and has in addition the great boon of allaying the dust almost or quite completely--a boon to grinders and machin. ery owners alike.

The apparatus consists essentially of an iron or steel pipe of any convenient dimensions (say, about four feet long, and about half an inch internal diameter). A piece of ordinary half-inch gas-piping has been found to answer well. Almost completely through this pipe one of smaller diameter is passed. By means of a bend, swivel, or otherwise this inner pipe is con of a bend, swivel, or otherwise this inner pipe is conof water can be obtained. The inner pipe may be adjusted within and prevented from slipping through the outer one by means of a collar and set-screw, sleeve, or other simple device. In conjunction with this pipe is used a box over the grindstone, to prevent splashing. This box is preferably of the length and breadth of the trough, and of such height as to allow the stone to revolve freely underneath. It may be made of wood, iron, or other waterproof material We have found that a wooden framework covered with waterproof oiled cloth suited admirably. About nine inches deep of the lower portion of the sides and end of the box are cut away opposite to those parts of the face and sides of the grindstone where the racing tool is to be used, and to allow for the axle and bearings. It can be supported in any convenient way to make up for this.

Racing is performed with the gas-pipe in a similar manner to that with the ordinary racing steel. A jet of water passing through the inner pipe splashes on the stone and mixes intimately with the stone dust imme diately on disintegration. The amount of this water supply depends on the size and quality of the stonea rate of a little less than one gallon per minute has been found sufficient for a stone nearly four feet in diameter, of moderate hardness.

The accompanying figure will explain the appliance. When a grinding stone revolves with a high angular velocity a considerable whirl is produced by friction with the air in the immediate neighborhood of the stone's periphery. If an article be pressed on its surface whereby particles of the stone and of the article are disintegrated, it will be found that the heaviest particles fly off in or near the direction of the tangent to the wheel at the grinding points. As we proceed from this tangent in the direction in which the stone is revolving, the particles get finer until some of the finest particles are carried right round the wheel by the whirl produced by the periphery of the stone. The behavior of these particles varies according to their mass, density, the speed at which they are thrown off, and the neighborhood of interfering objects or forces. To consider this behavior the whole spray of particles may be divided into four classes:

1. The heaviest, which fly nearly in straight lines for some distance, and then fall to the ground.

2. Those whose initial velocity diminishes rapidly, float about for a short time, and then settle down near the stone.

3. The lightest, which swirl from the peripheral current and float about, wafted by every eddy all over the room in which the grinding is done.

4. Those which are carried completely round the stone, and impinge again on the body or hands of the grinder, or on the article ground.

The proportions of each of these four classes in any particular case depend on: stone. (b) The nature, variety and size of the articles being ground.

(c) The amount of movement and pressure of the article on the stone.

(d) The situation of neighboring objects.

(e) The currents of air in the room affecting the articles.

Perfect ventilation is only secured when all four classes of particles are carried away, throughout every stage of the stone's wear. This must be done in such a manner that the progress of the work in hand is not impeded by reason of-

(1.) Obstruction of free movement of the grinder.

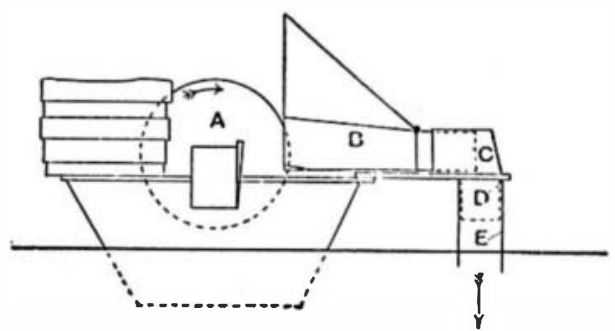

Fig. 2. -ADJUSTABLE HOOD.

B. Adjustable part of hood. C. Fixed
D. Adapter to fan pipe. E. Fan pip?.

(2.) Obstruction of free movement of the article eing ground.

(3.) Interference with the grinder's clear view owing to the lighting of the grinding surface being cut off.

(4.) Difficulty of removing the appliances fitte round the stone, to attend to it keeping in condition. These four sets of conditions have to be satisfied in general, and in particular when the effective ventila tion of any stone is being considered. The relative importance of the various conditions depends on the rades considered. In some trades the question of lighting is of prime importance, in others, of secondary, as the sparks generated by the grinding illuminate the stones sufficiently.

The removal of metallic and siliceous dust produced in quantity by rapidly revolving wheels or grindstones in the processes of grinding and glazing has always been deemed necessary for the good health of workers in these processes and those working in the same rooms. To effect such removal centrifugal fans have been almost invariably used, with ducts sucking air from the neighborhood of the stones or wheels. Many fan plants have failed completely because, relying on the analogy of gaseous fumes, the installers hav attempted to deflect the heavy dust particles by the air-suction current alone.

Observation of the actual processes, and consideraion of the vis viva of the particles thrown off, have ed to the conclusion that owing to the high initial velocity of the particles, approximating in most cases to a mile a minute, it is impossible effectually to remove dust so generated by the deflecting power of an air current alone. In other words, it is necessary to catch the flying particles, to destroy to a large extent their initial velocity, and then to deal with them by the air current. The larger the particles given orf in grinding the greater the force with which this principle must be applied. This general principle, obvious when demonstrated mathematically, was, I helieve. first enunciated in a practical manner quite recently by Mr. H. H. Cunynghame, C.B., a member of the Council of the Society of Arts. One is almost forced to conclude that this principle has beeis un- 
known to all, or certainly to the great majority of ventilating engineers, judging from the constructio of the plants installed. As a rule attempts have bee made to catch one or two of the four classes of particles, usually the first two. In order effectively to remove these without obstructing the lighting of the grinding surface, the hood fitted to the extremity of fan-duct opposite a stone has been placed at a comparatively great distance. Thus the third class of dust is only partially deflected, while the fourth is left unaffected. The consequence is that the most deleterious dust is left to be inhaled by the workers.

Again, sometimes the hood is fixed so as to intercept classes 2 and 3 , leaving classes 1 and 4 in the working room.

In no case has a hood capable of adjustment so as to intercept the fourth class been fitted, allowing at the same time of the grinding surface being illuminated.

Founded on the foregoing considerations, the fo lowing novel form of hood for dry grinding of razors, scissors, forks, augers, gimlets, etc., was devised by found effective in many instances.

It consists of a board or plate having a hole at on end, and means of connecting this aperture so as to form an air-tight joint to the fan-duct. Over this aperture is fixed a pipe of slightly larger area than the air duct. Into this slides a similar pipe on to which a suitably shaped hood is fitted. This hood which may have its top and sides constructed with glass panes to allow light to pass to the grinding surface, is kept with its lower edge close to the stone, and preferably overlaps the stone on either side. The device depends for its efficacy on the following point of construction:

First the height of the opening is such that the upper edge is above the tangent to the stone at
the furthest backpoint on the stone at which grinding may be done, thus catching class 1 dust; sec- ond, the width is the minimum consistent with the width of the stone and the extent to which dust siope of top and sides is allowed for, so that all siope of top and sides is allowed for, so that all
particles shall strike the hood at an oblique angle particles shall strike the hood at an oblique angle bottom comes close up to the stone, thus deflecting the a:r and tine dust whirl of the stone periphery and sides toward the duct; fifth, the top and sides may be constructed of easily removable strong sheet glass insuring translucency, with wire netting on each side to prevent fracture; sixth, as the stone wears down, the hood can be drawn forward so as to intercept class 4 dust throughout the stone's wear; seventh, the hood may be made capable of a second adjustment on the fan duct; the top of the hood may have hinges at its juncture with the sliding pipe, and so be raised or lowered as the size of the stone requires.

The accompanying figure (Fig. 2) will illustrate the appliance.-Journal of the Society of Arts.

\section{THE FORGING OF ALLOY STEELS." THE METALLURGY OF THE NEWER ALLOYS, \\ B Y E. F. L A H E.}

TrE alloyed steels, such as nickel, chromium, vanadium, silicon, tungsten, and several other alloys as well as different combinations of these, are comin into more general use every day for the parts of highgrade machinery which are subjected to a high rate of wear, which have to support a great weight or which re subject to excesive strains, stresses, and vibration. excessive strains, stresses, and vibration. used are too intricate in form to use the regular rolling-mill shapes and the alloyed steels have not, as yet been cast successfully, except in a few instances.

For these parts which cannot be produced from th rolling-mill shapes, or made in castings, forging is re sorted to, and there are several different ways of turning out these forgings: by hand, under a steam hammer, in a hydraulic press, or in a drop-forging press.

When small pieces and but few of a kind are wanted hand forging is undoubtedly the cheapest; but for hand forging is undoubtedly the cheapest; but for
large pieces, or where a large quantity is wanted, hand forging is the most expensive way of producing them and the strength is not apt to be as great as by any of the other methods. With a blacksmith shop properly equipped, a skilled smith can make forgings that are stronger than a rolled bar from the same ingot. To do this it must be hammered between the proper temperatures, which vary with different alloys of steel. A nickel-chrome steel must be kept at 2,200 deg. F. which is a bright yellow color, all through the forging operations, while some of the carbon steels, particuoperations, while some of the carbon steels, particu-
larly those that are high in carbon, cannot be heated to a temperature over $1,800 \mathrm{deg}$. F. without burning the metal; and when once burned it cannot be returned to its former state without remelting. The higher the carbon content the more danger there is of burning, and a steel of 1 per cent of carbon is very difficult to forge at all owing to the extremely low temperature at which it must be worked. The smith must also regulate the weight and effect of the blows so that it will be finished just as it reaches a blue heat. This will be finished just as it reaches a blue heat. This
will prevent the formation of large crystals, give the piece a dense, homogeneous grain with the atoms holding together by a high cohesive force and result in the steel having an increased strength.

In many of the more intricate shapes that are hand forged, recourse is had to welding, and if the average smith were told that he could not make a perfect weld, he would feel greatly insulted. But from a large number of so-called perfect welds that were examined ber of so-called perfect welds that were examined
very few showed a strength equal to 50 per cent of the unwelded section. With the alloy steels it is diffcult to get a weld that will even show that percentage as nickel, chromium, vanadium, tungsten, aluminium and some other alloys do not lend themselves to the welding process.

Carbon, however, is the principal enemy of welds and with this as low as 0.15 per cent it must be handled with great care at the welding heat, while with 0.20 per cent of carbon the steel is very unrewith 0.20 per cent of carbon the steel is very unre-
liable and with 0.50 per cent of carbon the steel is liable to be burnt at a temperature well below the welding heat.

Thus to make hand forgings where welds are necessary the pieces must be from two to three times the size of that necessary for the required strength and with some of the alloyed steel even this will not suffice.

Where electric or acetylene blowpipe welding is resorted to these bad features are overcome to a great extent and stronger welds are secured, as these methods melt the metal, allowing it to run together and then solidify, thus making a more perfect joint.

The steel which is the best adapted for forging under

the hammer has about the following composition: Carbon, 0.15 per cent; silicon, 0.20 per cent; mangan-
ese, 0.52 per cent; phosphorus, 0.06 per cent; sulphur, ese, 0.52 per cent
0.04 per cent.

This steel in the annealed state will show the following physical characteristics: Tensile strength, 55,000 pounds per square inch; elastic limit, 30,000 pounds per square inch; elongation in 8 inches, 29 per pounds per square inch; elongation in
cent; reduction of area, 60 per cent.

When fractured it will show a silky fiber.
Whention

But for many purposes a steel of much greater strength than this must be hand-forged and then it becomes necessary for the smith to understand the nature of its component parts so he can forge it successfully, as many of the high-grade alloy steels can be rendered no better or stronger than the ordinary carbon steels by over or under heating and poor workcarbon ste

In many cases welds are absolutely necessary to produce the required shapes and a steel of the follow ing composition is the best suitable for welding: Car bon, 0.08 per cent; silicon, 0.035 per cent; manganese 0.110 per cent; phosphorus, 0.012 per cent; sulphur, 0.007 per cent.

In the annealed state it should show the following physical characteristics: Tensile strength, 48,000 pounds per square inch; elastic limit, 25,000 pounds per square inch; elongation in 2 inches, 27 per cent. reduction of area, 69 per cent.

For such work, however, a nickel steel casting that is much cheaper than forging is being produced by one foundry that shows the following physical char acteristics: Tensile strength, 78,000 pounds per square inch; elastic limit, 50,000 pounds per square inch; elongation in 2 inches, 25 per cent; reduction of area 42 per cent.

Direct steel castings are being turned out by several foundries that show the following physical characteristics: Tensile strength, 70,000 pounds per square inch; elastic limit, 35,000 pounds per square inch; elongation in 2 inches, 25 per cent; reduction of area, 40 per cent These steel castings can be forged, welded, bent cold, tempered, and in fact worked about the same as rolled steel. The nickel-steel castings can also be case-hardened, and are successfully used in place of forgings.

For pieces of considerable size and bulk the steam hammer is substituted for the hand-forging process. In this method of forging the hammer should be of a size to suit the size of the work. The hammerman must exercise a good deal of skill and judgment as to the power and speed of the blows delivered to the piece, as a too powerful blow will crush it and in the cracks are liable to develop which it will be difficult to get out, and which may show in the finished product.

This is especially true if the piece is allowed to fall below the forging temperature, or if the blows are not distributed evenly. If the blows are from a light trip-hammer, delivered at high speed, only the surface of the metal will be bruised and the core not affected, thus causing the core to be coarse-grained without the proper adhesion to insure the necessary strength.

A heavy hammer descending on the work at a slow speed will penetrate the mass to the center and allow the particles of metal to flow to their proper position and insure a fine grain of even texture and be uniform throughout its entire size.

Cleaning of Alabaster.-To clean alabaster and reto rub with powdered talc. Other methods are: (1)
Immerse the objects in a solution of water and lime. (2) Benzine may also be employed, but it should be immersed, but washed with a cloth.

\section{TIMBER AND ITS PROTECTION FROM} MARINE ENEMIES.

A REC of the Royal Society of New South Wales contains a valuable contribution on the subject, as regards that state, of the metallic protection of timber exposed to the attacks of the teredo, from the pen of Mr. H. D. Walsh, M. Inst. C. E., engineer-in-chief to the Sydney Harbor Board. 'The marine enemies of the timber pile are the teredo, the Limnoria terebans, and the is not the same as that found in Europe. It attains a considerable size, and has been taken from one of the northern rivers of New South Wales as long as 6 feet and nearly $3 / 4$ inch in diameter. Its action is much more rapid than any other of the tribe, and it easily and quickly riddles timber of the density of turpentine is the a specific gravity of 1.3 . In fact, teredo dislikes, and this is on account of its nature, and not of its hardness, for it is one of the weakest of the native woods. The limnoria are small worms the native woods. The limnoria are small worms
about the size of a grain of rice, which attack only the comparatively soft woods, and they cause a very minute honeycomb, so that they do not cause much serious difficulty. The sphœroma are larger, but their mode of attack is different, as they erode the surface, and they are often the means of disclosing the internal ravages of the teredo, as the hole made by the latter is very small near the surface, increasing with penetration. In the earlier works, turpentine wood was largely used owing to its immunity, and piles of this material have been recently drawn, to make way for larger and heavier construction, which are perfectly sound after thirty to forty years' immersion, and in many cases they have been used for other purposes. Owing, however, to the quantity of the weaker piles required, and their extra bracing, etc., to obtain the requisite strength, ironbark piles sheathed with yeldurability of the sheathing used in the older works seemed to support this view. Ironbark piles protected by Muntz metal have been in use forty-eight years and are practically sound; in fact they have been ariven again in a new wharf. The protecting metal was worn slightly, but was sound, fairly flexible, and polished brightly, and there are other instances in coast works where the Muntz metal has been in good condition for over twenty-five years. Within the last few years, however, the metal supplied has been found to decay more rapidly; investigations were set on foot to ascertain the cause, and as the zinc disappears, leaving a brittle cellular copper skeleton, it is suggested that the modern electrolytic process in the production of copper, whereby chemically pure copper is attained, may have something to do with rapid corrosion. Advices from by the Muntz firm at a slightly greater cost, should be
by used. This has an addition of about 1 per cent of tin to the ordinary yellow metal, but there has not been sufficient experience of this expedient to test its suffciency. The coating of the metal inside with coal tar has been found to protect it from corrosion set up by juices from the wood.

Unless the sheathing can be restored to its former efficiency either concrete building must be adopted or turpentine timber, calling for a great bulk of material on account of its weakness, must be used. 